\title{
Re-Shoring and Resilience in Italy during and after the Crisis
}

\author{
Talamo Giuseppina, Sabatino Michele \\ Faculty of Business and Law, University of Enna "KORE", Enna, Italy \\ Email: giuseppina.talamo@unikore.it, michele.sabatino@unikore.it
}

How to cite this paper: Giuseppina, T. and Michele, S. (2018) Re-Shoring and Resilience in Italy during and after the Crisis. American Journal of Industrial and Business Management, 8, 1172-1196.

https://doi.org/10.4236/ajibm.2018.85081

Received: March 27, 2018

Accepted: May 13, 2018

Published: May 16, 2018

Copyright $\odot 2018$ by authors and Scientific Research Publishing Inc. This work is licensed under the Creative Commons Attribution International License (CC BY 4.0).

http://creativecommons.org/licenses/by/4.0/

\begin{abstract}
Since 1990s, companies have started to shift their productions to the low-cost countries and this strategy is commonly known as offshoring. However, over the past years, the evidence shows that offshoring strategies may not continue to be beneficial for the organization's companies activities. Consequently during the recent years, companies have begun to pay more attention to unquantifiable factors, such as the supply chain issue and strategy factors rather than simply relying on and the lowest price that in turn can mean the highest risk and high total cost. Having considered the discrepancy between the initially estimates cost of offshoring and those of actually occurred, companies are coming back through re-shoring strategies. In this paper, an overview of the main literature has been conducted to provide a better understanding of the term re-shoring. In the first section, various definitions and explanation of the concept of re-shoring will be presented. After that, the main motivations behind the re-shoring are discussed. The second part relies on the concept of resilience. We analyze resilience as a resource and response to the recent economic and financial crisis. In particular, this paper analyzes the role of economic resilience of the territories belonging to companies that have adopted offshoring strategies in the past and whether this has contributed to repatriation phenomena. In this regard, with the aid of recent data, we intend to understand the behavior of companies that have carried out re-shoring actions and their links with the economic resilience of the Italian regions. We also present whether there is a relationship at regional level between companies that have made re-shoring choices and the degree of economic resilience of a regional area. Finally, the critical considerations will be presented.
\end{abstract}

\section{Keywords}

Offshoring, Re-Shoring, Resilience 


\section{Introduction}

Over the past two decades, companies have started to shift their productions to the low-cost countries, following the offshoring strategy. This trend has been a structural and significant change of production procedures such as to render international production increasingly global and the offer of goods and services of a country increasingly dependent on the economic activity of other countries. From many parts emerged as the main characteristics of the offshoring strategies such as, lowest price can mean the highest risks and high total costs. Consequently, when it comes to manufacturing location decisions, the companies have begun to pay more attention to unquantifiable factors such as the supply chain issue and strategic factors rather than simply relying on cost [1] [2] [3].

Although offshoring has emerged as one of the most widespread strategies in order to maintain companies competitive advantages, in recent years, a counter trend has emerged: companies that had offshored their production, have started bringing production back [4]-[10]. Having considered that, in recent years, this has led the companies, in addition to the phase of the offshoring, to consider some new phases, including the re-shoring strategies in the country of origin of activities previously outsourced abroad. The same factors that, previously pushed to outsource production activities (the rising cost of labor, more costs of coordination and control, scarce quality of production processes, violation of industrial secrets), now seem to determinate a new phase for the strategies of relocation of productions.

On how to define the strategic decisions connected to reconsideration or a change of the previous choices of offshoring, there is a wide debate that gave rise to a terminological confusion to classify and to describe the phenomenon in itself. The re-shoring strategies in the country of origin, of production activities previously outsourced abroad, have been defined using several other terms: back-shoring, re-shoring, back-re-shoring, near-shoring, on-shoring, in-shoring. In the reminder of this paper, the label re-shoring will be adopted.

In this paper, we also consider the concept of resilience. The joint analysis of re-shoring and economic resilience is a missing link that could throw light on the evolution of regional and international strategies and could help to understand whether there is a relationship between re-shoring and the resilience of Italian regions. The more regions show resilience and recovery capacity, the more re-shoring strategies seem to be characterized by the ability of recovery. There has been a great interest on the part of economists also due to the recent economic and financial crisis. However, the definition and measurement methods have not yet been defined uniquely. The scientific literature raises some questions, in fact, on the ability that a territory has, following an economic shock, returning to the pre-shock levels in terms of economic growth, production, employment or other target variables. There is no unique definition of economic resilience and, as a result of this, there is no single way to identify the determinants and impacts. As part of economic and social disciplines, between 
multiple and more shared economic resilience definitions, we can mention the one adopted by the EU which defines it as the ability of a "system to withstand, absorb or overcome an external shock" and to maintain and/or return to the pre-existing state [11].

The paper is organized as follows. In the next section an explanatory literature review has been conducted to provide a better understanding of the term re-shoring. This work aims to clarify the terminological ambiguity that came about and discusses the determinants of this new phenomenon that are the center of a heated debate. Re-shoring could be related to a strategic decision of the companies, as a consequence of the complex process phase of the internationalization of companies, that over time has damaged the advantages of ownership, location and internalization, and that aims to re-organize production activities on safety procedures, high quality, proximity to customers, as an answer for new patterns in economic consumption [1] [12] [13] or a mechanism to correct managerial mistakes made at the moment of the initial decision of off-shoring, as conceptualized by [7]; or an adaptation to new patterns in consumption matters, such as the made-in [14]. Section 3 presents a detailed analysis of the resilience in general and economic resilience in particular. In Section 4 we discuss the research framework and the relation between re-shoring and economic resilience. Section 5 presents some results. We conclude with a discussion of results and limitations.

\section{Re-Shoring: Analysis of the Main Literature}

While theories on offshoring have been extensively discussed in the literature, the theoretical explanations on re-shoring are more fragmented. In this respect, although several theoretical perspectives have been proposed, many re-shoring studies are not theory-based. There is a wide debate that gave rise to a terminological confusion to classify and to describe re-shoring: back-shoring, home-shoring, re-shoring, back-re-shoring, on-shoring, re-distributed manufacturing [2]. It should be noted that each of the above label is used in different countries, for instance, re-shoring is mainly used in United States and United Kingdom, whereas back-shoring and back-re-shoring are used in Germany and Italy.

In the literature that reversing the offshoring decisions is not a new phenomenon. There have been a number of studies performed under different titles such as "de-internationalization" and "international divestment". [12] defines de-internationalization as any activities, voluntary or compulsory, that decrease a company's engagement in present cross-border activities. The analysis was carried out from three theoretical perspectives: economic, strategic management and internationalization management. The concept of international divestment defines the reduction in the level of ownership in company's direct foreign investment regardless of decision voluntariness. However, these concepts, de-internationalization and international divestment, lack some of the key features of re-shoring such as outsourced production. In addition, these studies 
do not particularly consider the relocation of facilities back to the home country.

In [5] and [15] define the return of production activities from the host country to the home country having reference to re-shoring, a term mainly used in the USA. Re-shoring means a strategic decision regarding the place where to move the production. Depending on the return of production activities (in-sourcing or outsourcing) the authors identify four re-shoring procedures: i) in house re-shoring: when the previously outsourced production activity returns to be part of the company of the country of origin; ii) outsourcing re-shoring: when the previously production object of the outsourcing moved from the foreign supplier to the country of destination; iii) re-shoring for outsourcing: if the production activities previously managed in foreign factories of the company are after, when repatriated, handed over to third suppliers (compared to the parent company) of the country of origin; iv) re-shoring for in-sourcing: in which the production previously outsourced is directly internalized in the domestic production units. In [16] defines back-shoring as follows: "the geographic relocation of a functional, value creating operation from a location abroad back to the domestic country of the company". The author underlines how, the concept of back-shoring, mainly used in Europe, cannot be meant as a disposal abroad or a divestiture, rather as the relocation of the company to the country of origin of value activities localized in international geographical contests. It is about, therefore, a return of manufacturing activities in national factories owned by the company or carried out from suppliers present in the same country of the parent company. Moreover, [16] contrasts back-shoring to back-sourcing defining this last as a relocation regarding production activities entrusted to suppliers that operate in the same country in which the company has based its headquarters. To this company choice can be related the terms indirect back-shoring (Renz, 2005) and external back-shoring [7].

In [7] (p. 155) define back-shoring as a "re-concentration of parts of production from own foreign locations as well as from foreign suppliers to the domestic production site of the company". The authors underline the repackaging of a production unit into the home country of a production activity previously carried out abroad in factories owned by the company or by local suppliers. In [8], have conceptualized the aspect of the re-concentration as the production capability, that takes advantage from the benefits of the use of a higher production capability and a higher relation of variable costs, "correcting" the locality and focusing on how, for the re-concentration, it is necessary a previous production carried out abroad. In [17] building on different cases of re-shoring, has identified, since 1980, four waves of back-shoring that take into consideration the following criteria: the country; the headquarters of the company; the industrial sector; the reasons that have pushed the company to outsource. The first wave of back-shoring coincides with the start of the automation of the production process, thanks to which it was possible to reduce production costs and in particular those relative to the labor. This has levelled the competitiveness in labor costs between the host country and the country of origin. The second wave 
mainly concerns the German industrial sector, that already registered in the first half of the $80^{\prime}$, some back-shoring cases ${ }^{1}$. The third wave concerns other European countries that following the example of German companies have adopted the strategy of back-shoring ${ }^{2}$. The last wave can be allocated at the beginning of the new Millennium³ ${ }^{3}$.

The existence of re-shoring cases also seems interesting for managerial implications. A part of the literature (among other also Kinkel and Maloca, 2009) affirms that these choices are the consequence of some previous corrections of managerial mistakes regarding the decision to outsource production activities. Other authors (amongst others also [1]) state that, beyond the assumption of a mere correction of previous managerial mistakes, it may also take into consideration the deterioration over time of the existent conditions at the moment when the decision to outsource was made. In [1] [2] [3] proposes a definition "operative" of back-shoring, in other words a definition of a summary of theoretical concepts proposed in the academic and managerial fields: back-re-shoring. Back-re-shoring means: "a-deliberate and voluntary-company strategy that aims to domestic relocation (partial or total) of activities carried out abroad (directly or through suppliers) in order to face the local demand, regional or global' ([1] p. 131). The authors suggest a dynamic approach to international localization procedures of companies, and identify in the back-re-shoring one of the phases of the development of manufacturing activity at international level. According to [17], the quality and cost issues are unlikely to be the only reason for the long-term repatriation of production from low-cost countries. Instead, it is believed that the only way for a long-lasting and sustainable re-shoring strategy is fundamental transformation of the current industrial production, which is also called reinvented manufacturing. In other words, it will not be economically feasible to repatriate the same manufacturing tasks that were previously offshored due to factors such as high labor and energy content. Therefore, the new generation of manufacturing activities is required to adopt modern technologies by which industries will ensure their competitive position in the market. One of the major focuses in the concept of reinvented manufacturing is the personalization of the product by moving from mass production towards mass customization in order to address the ever-changing customer expectations. By doing so, the industries can achieve higher variety while keeping the volume low [17] 1565).

\section{Focus on Re-Shoring in Italy}

The re-shoring phenomenon is also of interest to the Italian production system,

${ }^{1}$ Bosch is one of the first case of German back-shoring.

${ }^{2} \mathrm{We}$ are at the beginning of the '90s and the sectors interested are: Electronics, in particular, but also textile. Some example: Nathan for toys; Sagem for mobile phone; Essilor for glasses; NafNaf and Caroll for clothing.

${ }^{3}$ For example, Nokia, since 2014 Microsoft Mobile, after three and a half years of permanency in Romania decided to return the production to Finland. 
characterized more in general by significant reconsiderations of the production models and internationalization strategies as an answer to the recent crisis. In this paragraph, an overview on its diffusion, with a reference to the most significant company cases interested in adopting strategies to repatriate the production activities based on the available information deduced by available sources, will be provided. [1] [3] [18] [19] [20].

From [18] findings it come to light that Italy is the second country in the world, after the USA, and the first in Europe, for the number of repatriations of production activities outsourced abroad, with a rate of $20 \%$ on a global scale and around $42 \%$ on a European scale [3].

From 1997 to 2001 the number of back-shoring cases in Italy registered a decreasing trend and subsequently remained constant up to 2006. In 2007 a relevant increasing was evident, to reach its peak in 2009 with 17 cases, reducing to one third in 2010. The last positive variation of the number of companies that back-shored to Italy occurred between 2011 and 2012, the year in which the number of companies quadrupled reaching quota 12 . Moreover, in analyzing data, it is necessary to consider that companies, depending on their dimensions, have carried out more than one re-shoring operation and that the results regarding 2009 and 2015 are the consequence of the fact that the crisis has been incisive on the Italian economy [18].

Considering the specialization sectors of Italian companies it comes to light that, as it happens at global level, in Italy the sector where more cases of re-shoring occurs are those textile-clothing and footwear (43\%). $12 \%$ is represented by the automotive sector, $18.6 \%$ electric, electromechanical and electronic. 5.8\% furniture and household appliance; while biomedical, cosmetics and mechanical count only $4.7 \%$ of the back-shoring cases, even less $(3.9 \%)$ heavy goods vehicles, food, pharmaceutical, textile and toys (1.2\%). From the data it emerges that $33 \%$ of Italian companies which adopted re-shoring strategy had outsourced their own activities in China, 24\% in the Eastern Europe and in Russia, 3.3\% Africa and Middle East countries, $1.7 \%$ in North America and 12.4\% in other Asian countries [18].

Considering the reasons that push Italian companies to re-shoring, made-in is the most frequent reason (42\%). $24 \%$ of the cases, instead, concerns the poor quality level of the production; $21 \%$ the necessity of more attention to the customer's needs; $18 \%$ the social pressure of the country of origin; $16 \%$ the highest level of competences of the workers of the country of origin; $13 \%$ a higher production capacity after the economic crisis; $13 \%$ the reduction of the difference regarding the labor cost. In relation to repatriation in Italy the logistic costs and production costs seem to be negligible (11\%), on the contrary of what happens at global level, and in particular in the USA. This can explain the elevated gap in terms of labor costs of our country compared to those of traditional outsourcing [18].

The data, confirm, that, there are different reasons that pushed Italian companies to adopt re-shoring strategies: not only economies of scale, studied advantages and global planning networks, production and distribution through the 
insertion of the companies in value global chains extended to more countries and markets, coordinated by multinational companies [21] [22], but also other forms like, to be competitive oriented on high quality, innovation, safety and made-in. In the end, also redundancies of personnel and the availability of unused production in Italy have been, at times the motivation to adopt back-shoring strategies, especially when labor unions agreed to increase the production per hour worked (for example Natuzzi and Safilo cases, [3]).

In Italy, a further increase of the phenomenon is due to the imitative effect of back-shoring. When some companies, increasing the use of local suppliers, have noticed that many customers/competitors had already moved their productions back to the country of origin, or sought productions made in Italy, have re-evaluated the link with the territory of origin. Therefore, the start of back-shoring flows of productions outsourced abroad had pushed several companies, specialized in certain kind of activities carried out behalf of big Italian brands, to back-shore their production to the country of origin [23].

Considering the geographical location, it comes to light that back-shoring strategy in Italy mainly concerned the northern regions (97 decisions on 123), first of all Veneto (36), Emilia-Romagna (22) and Lombardy (18). At macro area level, the northwest has involved 43 companies that mainly back-shored from China and other Asian countries, while North East 36, mainly coming from Eastern Europe and the Balkans. In central and southern Italy, instead there are few cases. The companies that have back-shored their productions to the central regions are 17: 7 in Tuscany, 7 in Marche, 2 in Umbria and one in Lazio. Re-shoring has interested 5 companies from the South of Italy: 2 in Apulia, 2 in Campania and one in Abruzzo; Sicily and Sardinia are not available [18].

The data presented in Table 1 show that the gap between North and South, in company re-shoring procedures cannot be taken into consideration. This confirms the close relationship between the geographical distribution of investments and the one related to re-shoring.

Considering these recent data and some new projects, we can conclude that in Italy, to facilitate re-shoring phenomenon little has been done. The important trade associations, in particular in the sectors of fashion and footwear, have been asking for a long time to put into effect the planned tax reforms, regarding IRAP and hiring in order to facilitate the back-shoring. One of the main reasons of back-shoring for Italian companies is the made in Italy. In this regard, it has been recognized as a central role to consumers and international markets because of an increasing demand of productions completely made-in Italy [14]. The necessity of more attention to customers' needs has, pushed companies to reconfigure their supply chain on an international scale, also because of the pressure caused by the crisis. Italian companies that have adopted re-shoring strategies mainly connected to the added value of made in Italy, require, also, an improved legislation regarding the certification of the origin of the productions, that could guarantee a greater protection of the made in Italy. 
Table 1. Re-shoring in Italian regions.

\begin{tabular}{|c|c|c|c|}
\hline GEOGRAPHIC AREA & REGIONS & RE-SHORING & TOT \\
\hline \multirow{5}{*}{ NORTH WEST } & Emilia Romagna & 22 & \multirow{5}{*}{52} \\
\hline & Lombardia & 18 & \\
\hline & & & \\
\hline & Piedmont & 7 & \\
\hline & Liguria & 5 & \\
\hline \multirow{3}{*}{ NORTH EAST } & Veneto & 36 & \multirow{3}{*}{45} \\
\hline & Friuli Venezia Giulia & 6 & \\
\hline & Trentino Alto Adige & 3 & \\
\hline \multirow{5}{*}{ CENTER } & Marche & 9 & \multirow{5}{*}{22} \\
\hline & Tuscany & 9 & \\
\hline & Umbria & 2 & \\
\hline & Lazio & 1 & \\
\hline & Abruzzo & 1 & \\
\hline \multirow{2}{*}{ SOUTH } & Apulia & 2 & \multirow{2}{*}{4} \\
\hline & Campania & 2 & \\
\hline TOT & & 123 & 123 \\
\hline
\end{tabular}

Source: Uni-CLUB MoRe Back-re-shoring Research Group, 2016, Eurofound.

Recently some initiatives have been promoted in order to support Italian companies that want to pursue a re-shoring strategy. In this regard it is interesting to analyze the "Project re-shoring", which came about from the collaboration between "Sistema Moda Italia" (SMI) and PwC Advisory, that it is oriented to create the necessary conditions to back-shore the productions and to increase the productivity in two pilot areas, Veneto and Apulia. The project aims to promote assistance to companies, re-qualification and education through an Academy but also to collect acceptances by those companies, and mainly by PMI, that intend to carry out back-shoring ${ }^{4}$. SMI has created new contacts with the manufacturing companies and it controls the state of the project in order to expand it to other Regions. The district of the production chain relative to Veneto has been chosen for several companies present both upstream and downstream of the sector: the production chain is made up of clothing companies, textile, third party companies, machinery and material suppliers, service suppliers, wholesalers and distributors as well as intangible services. Apulia, represents, instead, the first southern region in textile-clothing, both for the number of active companies and for the number of employees (footwear in the North of Bari, Clothing in Bari, Hosiery and Clothing in Salento, footwear of Casarano) that boast handcrafted excellence. The Apulia Fashion District, has been affected by the recent economic negative phase, that has caused a great

${ }^{4}$ According to the observatory $\mathrm{PwC}, 76 \%$ of controlled companies have modified, or have the intention to do so, the suppliers in the last ten years, in the majority of the cases, less than $25 \%$ of the production is carried out in Italy. 
weakening and it aims, through "Project re-shoring", to contribute to backshore production in Apulia and activate a virtuous circle in order to expand the project to other regions. The "Project re-shoring" will work by educational interventions and re-qualification of personnel, supporting investments regarding R\&S in order to give a concrete result to reach the recovery of the territory. Another example of initiatives to facilitate back-shoring is represented by "Laboratorio Moda Molise"s, that aims to give value and guarantee scientific, professional, and manufacturing competences of the made in Italy sector through instruments and policies of traceability and certification, as well as to promote company cooperation by means of contact and collaboration also with national and international authorities. The Region of Molise has also signed a protocol of partnership with "Missardi Ltd.", a company leader in the fashion industry, in order to re-launch the sector with made in Italy creations.

Moreover, it is interesting the strategy adopted by "Natuzzi". This company in 2013 signed an agreement, defined as "historical", at the Ministry of Economic Development with the Government and the Regions of Apulia and Basilicata, that aims to create new opportunities for all the territory in terms of competitiveness, in particular regarding the area between the provinces of Bari, Taranto and Matera. The main points of the agreement are: investments for more than 200 million euro; re-qualification of a large part of the personnel; the creation of two new companies, by order of the "Natuzzi Group", that thanks to the back-shore of productions to Italy, previously outsourced in Romania, can carry out, the first line of sofas currently produced in Romania (500 employees in 2014 that will increase up to700 in 2018), the other, furniture components (150 employees). The creation of new activities, which are favored by the resources (101 million of euro) allocated by the Agreement, aims to reuse around 220 employees, facilitating voluntary labor mobility for 600 employees, blocking more than 1.700 redundancies. In this way the attempt is to create a sort of contrary delocalization, from Romania: this is something very new that represents the peculiarity of the Agreement and it opens new interesting possibilities for the Italian economy. "Natuzzi" represents an important example for other companies: it is possible to divert the work flow brought abroad, coming back to Italy, and also returning to Italy those productions with a high rate of work.

In addition to made-in, also the factor time-to-market is becoming more determinant for Italian companies that decide to adopt back-shoring strategies: to promptly answer consumers requests is a successful key factor and those companies which can make it have an enormous advantage on their competitors. Therefore, it is necessary, to move at least part of the production close to faster production cycles in order to keep in pace with other markets. In the light of the present examples, we can conclude that back-shoring can represent a great opportunity to develop the economy of Southern Italy.

${ }^{5}$ Laboratorio Molise, promoted by EURIDIT, with the Province of Isernia and the Municipality of Pettoranello. 


\section{The Concept of Resilience.}

The word "resilience" comes from the latin verb resilire, that is to rebound. The term is first applied to engineering and ecology in the scientific field. But still today there is nether a univocal definition of resilience nor an only way to focus the decisive factors of it and its effects [24] [25]. Resilience may be interpreted in three different ways.

The first definition is from engineering [26] [27] [28] [29] [30]: resiliency is defined as the speed of a system to return to the previous position, as a consequence of a disturbance "how fast a system that has been displaced from equilibrium by a disturbance or shock returns to that equilibrium". For this, the system has to be able to reach an equilibrium by itself: every shock which leads it to a situation of no equilibrium will start up a series of mechanisms to come back to the equilibrium before the shock. So a system that is more resistant to shocks or that quickly returns to its pre-equilibrium shock is considered more resilient to a system which, when subjected to the same shock, not only has a much more pronounced reaction to it, but also requires more time to return to its steady state. In Figure 1 we can see the engineering resilience. Vertical axis we find the occupation and the horizontal axis time. The growth trend is constant and despite the shock, the system will return to equilibrium recovering the growth path from where it would have been if there had not been the shock [24].

The ecological resilience [26] [27] [28] [31] [30] is the ability of a system to absorb a disturbance without changing its structure, identity and functions. In this case the focus is on the stability of the system and the size of the shock which may be faced before the system moves to another state "the capacity of a system to absorb disturbance and reorganize while undergoing change so as to still retain essentially the same function, structure, identity and feedback' [30].

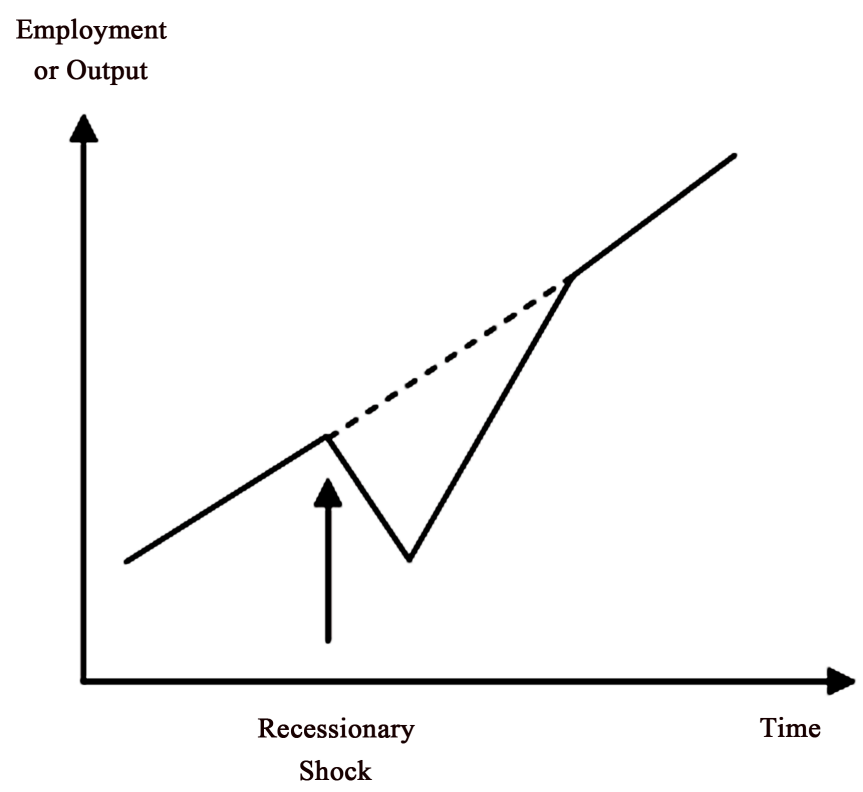

Figure 1. Impact of a shock according to the engineering resilience. 
The ecological approach ranks in a context of adaptive cycle, within the regional sciences. The ecological resilience has been studied by the ecologist 32 since the early 70s. Starting from Odum's studies and a deep analysis of the characteristics of the complex systems and the adaptive behaviours, he has introduced a complex definition of the Social Ecological System resiliency. According to [28] the resilient Social Ecological Systems are able to evolve, because of a disturbance, to multiple states different from the one before the disturbance, keeping the essential functions and restoring the structures which distinguish them. According to this approach, the resilience of a system is its ability to bear a disturbance, contrasting the consequent increase of entropy. This ability lets the system pass to a different equilibrium system, generally inferior, with a different composition of the processes and then know a sort of functional crisis. In a resilient system the change can create opportunities and development: the system cannot only recover, with time, a situation identical or similar to the previous one but, through the learning processes, it can also introduce variations producing important and positive innovations. The third and last definitions of resilience, adaptive resilience, is defined as the ability of a system to react to a stress without loosing the capacity to allocate resources efficiently "the ability of the system to withstand either market or environmental shocks without loosing the capacity to allocate resources efficiently") ([32] p. 418). The concept of adaptive resiliency, within the Evolutionary Economic Geography theory, may be interpreted in terms of regional economy, as the ability of the different regions to withstand the changes and the shocks in a competitive market focusing the attention on the dynamic of the process and the movements developing with time [25]. It may, therefore, be interpreted as the ability of recovering after a shock as well as the ability to re-set its growth [33]. A resilient region is not only a virtuous one but a region able to be successful in time, adapting its ways of growth. If a way of growth is not longer good, other ways may be taken thanks to a process of repositioning and reorganization [34]. It requires adaptability and adaptation to the changes of the territory. The elements which make a region adaptable and easy to adaptation are: a strong regional system of innovation [35], the elements which make a learning region [36], the presence of competitive infrastructures and transports, a labour with a good education level, a financial system which may support the enterprises, a diversified industry competitive in different fields. The resilience of a region or territory is, therefore, the ability of a local and regional economy of modifying its own industrial, technological, institutional structure according to the change. If the shock is strong enough, it may alter the behaviour of the economic factors, change the economic system and move it to other directions [37]. The resilience is a high as the ability of the system to react to the shocks with creativity and flexibility [37].

All that depends on the innovative abilities of the enterprises, the ability of the enterprises to create new opportunities, the structure of the credit market and the attitude of the institutions to be innovative, and finally on the ability of the individuals and community to react in a flexible and innovative way. 
In Table 2, [24] explains synthetically the passage, within the theory of the systems, from engineering interpretation of resilience and vulnerability to an ecological and finally systemic adaptive interpretation.

Finally the concept of resilience is used today in a variety of discipline fields even if it is not clarified [34]. The difficulty of interpretation is also in the use of different concepts which are more often associated with it (learning region, adaptability, etc.). However, this does not inhibit rather stimulates a wider a multidisciplinary scientific debate both as a theoretic approach and empirical with reference to the measuring of the phenomenon in analysis.

However, the concept that is closest to our research objectives is referred to that of economic resilience. As part of economic and social disciplines, between multiple and more shared economic resilience definitions, we can mention the one adopted by the EU which defines it as the ability of a "system to withstand, absorb or overcome an external shock" and to maintain and/or return to the pre-existing state [11]. Then it refers to the economic flexibility to change, adjust, adapt later to shock [38]. Studies on resilience, until recently, had not been used widely in regional economic literature and, where present, had been limited to developing countries [39]. [40] Briguglio states in 2003 the so-called "Paradox of Singapore", referring to the economic development of a number of small countries (Singapore and the islands of Malta and Cyprus). According to the author, despite its small territorial size and the high exposure to external shocks (high vulnerability), the economies of small states observed are able to achieve and sustain significant levels of economic growth thanks to their resilience. Only now, following the financial and economic crisis of 2007-2008 and the rough handling due to the globalization and international competition, has developed a line of study both in regional economy and in the entrepreneurial and business systems, able to understand how a territory and its businesses can react to strong economic and social stresses. Considering the level of risk that characterizes the

Table 2. Resilience and systemic vulnerability.

\begin{tabular}{cl}
\hline Approach to the study of resilience & \multicolumn{1}{c}{ Focus } \\
\hline Engineering & $\begin{array}{l}\text { Ability of a system to return after the disturbance to the } \\
\text { original equilibrium. The focus is on the condition of } \\
\text { stability around the equilibrium point (Odum, 1965) }\end{array}$ \\
& $\begin{array}{l}\text { Quantity of a disturbance a system can absorb before } \\
\text { falling in a condition of equilibrium of inferior level, } \\
\text { governed by different set of processes. The focus is on } \\
\text { the behaviour of the system "oriented to equilibrium". } \\
\text { The approach implies the existence of } \\
\text { multiple equilibriums (Holling, 1973) }\end{array}$ \\
Adaptive system (socio-ecological) & $\begin{array}{l}\text { Ability of the system to advance the change as a } \\
\text { consequence of an unforeseen event to minimize the } \\
\text { negative impact. The focus is on the adaptive abilities } \\
\text { of the system and the learning mechanism } \\
\text { (Carpenter, Walker, Holling 2001; Folke, 2006) }\end{array}$ \\
\hline
\end{tabular}


era in which we live, it is therefore important to understand how and why some regions are more successful than others to overcome moments of difficulty and crisis. Unlike an economically resilient system, where change has the ability to renew and introduce positive innovations, non-resilient systems, so vulnerable, have a high risk related to negative impacts arising from unexpected shocks.

The literature on economic resilience has also highlighted the role of the composition of the production fabric. In general, regions with a diversified economy are considered less vulnerable to external shocks than some areas in specialized sectors. Among the factors that could explain the difference ability of the territories to adapt to external shocks are included the innovation system, institutions, entrepreneurship. The list of possible determinants of resilience of an area is potentially very wide. Also, in this case there is no unique definition of economic resilience and, as a result of this, there is no single way to identify the determinants and impacts.

\section{Methodology}

The purpose of this paper is to verify whether the economic resilience of the Italian regions belonging to enterprises that had initiated the delocalization processes in the past and had contributed to the re-shoring phenomena. In this regard, we intend to understand the behavior of companies that have carried out re-shoring strategies and their links with the territorial and regional area, and hence the economic resilience of the Italian regions in the face of most recent economic and financial shocks that has contributed to these types of business and production choices. The aim is to demonstrate that there is a relationship at regional level between companies that have made re-shoring choices and the degree of economic resilience of an area.

The work is based on the recent data from [18] concerning the phenomenon of the adoption of repatriation strategies for the production activities of enterprises that had, in the past, initiated delocalization processes. Data show and confirm divisions between the regions of the North and the regions of Southern Italy, but also some concertation in three regions of Italy that represent territorial areas rich in district and network experiences. At the same time, agreeing to the validation of the study of [41], a measure of economic resilience is shown that can represent the reactions of the Italian regions at different stages of the most recent economic crisis using a relevant indicator such as the rate of employment. By defining a economically resilient region, the one that can, following a shock, on the old growth path or find it new in a relatively short period of time, has emerged that there are Italian regions that reacted more resiliently to face with the economic shocks and much less resilient regions. Following recent literature suggestions that highlight the difference in the range of economic and social resilience capabilities that may vary considerably to the back-shoring phenomenon in different Italian regions, this result was used to study whether the regions that had a lower employment decline, but above all, increased resis- 
tance and recovery capacity were also those characterized by recent phenomena of repatriation of productive activities. If the hypothesis is confirmed, it can be concluded that regions reporting significant re-shoring phenomena are those that have reacted more resiliently than others.

Initial hypotheses, however, were only partially confirmed. The analysis has shown that only for some regions there is a significant correlation between the economic resilience index and the re-shoring phenomena. Regions with a higher level of resilience are those who reacted better to the latest economic shocks and also show significant returns experiences of production activities. However, there are also some regions that, despite the significant presence of resilience, have failed, like the others, to convince the business system to repatriate activities and productions.

We can conclude that the presence of a capacity to resist and, above all, regenerate at the regional level it is necessary but not an indispensable element of the re-shoring phenomenon as in the business-level, the production and location choices also contribute to other dimensions of other nature referring, for example, to the country of delocalization of the initial introduction, to the international and national development, to the productive and entrepreneurial characteristics of the company, to the degree of openness and innovation or to other institutional and political dimensions.

\section{The Results of the Analysis}

\subsection{The Resilience of the Italian Regions}

For the resilience analysis we proceed taking a cue from recent research. In particular, we used the results of a study on the resilience of the Italian regions proposed by [41] and inspired by [24] according to which the changes in the regional economies after an economic shock consist of two phases: the first is the same shock while the second is the recovery phase. Resilience is thus the adaptability of regions in bearing shock due to an economic recession. The focus of analysis is given of data on employment and the source is Prometeia. The study analyzes in particular the three most recent economic crisis (1970-1973; 1992-1995; 2008-2010) and the two periods of recovery and growth (1973-1991; 1996-2007). In particular, the first shock is identifiable in the period 1970-1973 where the decline in the employment rate is mainly due to the oil crisis. The second shock is identifiable in the period 1992-1995 due to the devaluation of the Lira, the scandals and corruption at a time of serious political and economic instability. The last recession, is that related to the economic and financial crisis of 2008-2010, which broke out in the United States, has spread rapidly in Europe and Italy. The study of Lagravinese [41] proposes to measure the capacity of resilience of the Italian regions through the determination of a resistance index and a recovery index.

The resistance index

The resistance index is calculated as follows: 


$$
\beta r e s=\left|(\Delta X r / X r)-(\Delta X N / X N)^{E}\right| /(\Delta X N / X N)^{E}
$$

where $\mathrm{E}$ represents the expected national growth during the recession period. $(\Delta X r / X r)$ and $(\Delta X N / X N)$ are the percentage changes in employment, respectively, at the regional and national level. A positive value of this index indicates that the region has a higher resistance to an adverse shock than the rest of the country, a negative value indicates that it is less resistant, finally a value of zero indicates that there is no difference. The following table (Table 2) presents the index of resistance values for the 20 Italian regions during the three periods of recession.

The data in Table 3 show that in the first recession (1970-1973) the main affected regions were Umbria (-4.49) and Friuli Venezia Giulia (-3.76). In the second recession, however, the most affected regions were Sardinia $(-1.08)$ and Sicily (-0.87). Finally, the most recent recession (2008-2010) was most severe in the Campania (-1.13) and Basilicata $(-0.70)$.

\section{The recovery index}

The recovery index calculated in the post-recession periods, 1974-1991 and 1995-2007 is calculated as follows:

Table 3. Index of resistance in employment contraction in the three recessions.

\begin{tabular}{|c|c|c|c|}
\hline & $1970-1973$ & 1992-1995 & $2008-2010$ \\
\hline Piedmont & -2.13 & 0.10 & -0.10 \\
\hline Valle d'Aosta & 3.07 & -0.85 & 0.66 \\
\hline Lombardia & 0.93 & -0.01 & -0.08 \\
\hline Trentino Alto Adige & 3.98 & 0.15 & 1.19 \\
\hline Veneto & 0.37 & 0.55 & 0.55 \\
\hline Friuli-Venezia Giulia & -3.76 & 0.22 & -0.07 \\
\hline Liguria & 0.31 & -0.78 & 0.31 \\
\hline Emilia-Romagna & -1.27 & 0.51 & 0.19 \\
\hline Tuscany & -2.21 & 0.31 & 0.45 \\
\hline Umbria & -4.49 & -0.05 & -0.15 \\
\hline Marche & -2.43 & 0.32 & 0.71 \\
\hline Lazio & 2.45 & 0.15 & 0.27 \\
\hline Abruzzo & 4.76 & 0.08 & -0.50 \\
\hline Molise & 0.41 & -0.09 & -0.14 \\
\hline Campania & -0.99 & -0.31 & -1.13 \\
\hline Apulia & 5.42 & -0.51 & -0.65 \\
\hline Basilicata & -0.37 & 0.34 & -0.70 \\
\hline Calabria & -2.17 & 0.39 & -0.34 \\
\hline Sicily & -2.75 & -0.87 & 0.02 \\
\hline Sardinia & -0.53 & -1.08 & -0.06 \\
\hline
\end{tabular}

Source: data-base Prometeia. 


$$
\beta r e c=(\Delta X r / X r)-(\Delta X N / X N)^{E}
$$

A value greater than 1 indicates a strong recovery after the recession period, a value less than 1 indicates a weaker recovery than the rest of the nation, a value of zero indicates no difference. During the first post-recession (1974-1991), Lazio (1.84), Trentino (1.61) and Valle d'Aosta (1.66) have been growing faster than the southern regions (made except for Sardinia 1.83 and Puglia 1.10). In the second post-recession period, the central regions, such as Lazio and Umbria, showed a higher recovery ratio (1.73 and 1.45), respectively. Table 4 shows the index recovery of the values for each region.

In order to proceed to the measurement of resilience Lagravinese [41] suggests, for each region, to calculate the average index of resistance, calculated over the three periods of recession and recovery index, calculated in the two post-recession periods. The resilience rating $\beta R$ thus obtained will be equal to the ratio between the resistance index and the recovery index. The following $\mathrm{Ta}$ ble 5 shows the Rank by resilience rating of each Italian region.

Table 4. Index of employment recovery in the post-recession periods.

\begin{tabular}{ccc}
\hline & $1973-1991$ & $1995-2007$ \\
\hline Piedmont & 0.53 & 0.83 \\
Valle d'Aosta & 1.66 & 0.91 \\
Lombardia & 1.20 & 1.11 \\
Trentino Alto Adige & 1.61 & 1.18 \\
Veneto & 1.19 & 1.18 \\
Friuli-Venezia Giulia & 0.58 & 0.63 \\
Liguria & 0.38 & 0.55 \\
Emilia-Romagna & 0.86 & 1.14 \\
Tuscany & 0.98 & 0.99 \\
Umbria & 0.99 & 1.45 \\
Marche & 0.43 & 1.09 \\
Lazio & 1.84 & 1.73 \\
Abruzzo & 1.15 & 0.57 \\
Molise & 0.21 & 0.93 \\
Campania & 0.77 & 0.67 \\
Apulia & 1.10 & 0.53 \\
Basilicata & 0.11 & 0.69 \\
Calabria & 0.70 & 0.48 \\
Sicily & 0.76 & 0.80 \\
Sardinia & 1.83 & 0.93 \\
\hline
\end{tabular}

Source: data-base Prometeia. 
Table 5. The Rank by resilience rating of each Italian region.

\begin{tabular}{|c|c|c|c|}
\hline & Resistance Index & Recovery Index & Resiliece Index \\
\hline Piedmont & -0.71 & 0.68 & -1.04 \\
\hline Valle d'Aosta & 0.96 & 1.28 & 0.75 \\
\hline Lombardia & 0.28 & 1.15 & 0.24 \\
\hline Trentino Alto Adige & 1.77 & 1.39 & 1.27 \\
\hline Veneto & 0.49 & 1.18 & 0.41 \\
\hline Friuli Venezia Giulia & -1.20 & 0.60 & -2.00 \\
\hline Liguria & -0.05 & 0.46 & -0.11 \\
\hline Emilia Romagna & -0.19 & 1.00 & -0.19 \\
\hline Tuscany & -0.48 & 0.98 & -0.49 \\
\hline Umbria & -1.56 & 1.22 & -1.28 \\
\hline Marche & -0.47 & 0.76 & -0.62 \\
\hline Lazio & 0.96 & 1.78 & 0.54 \\
\hline Abruzzo & 1.45 & 0.86 & 1.69 \\
\hline Molise & 0.06 & 0.57 & 0.10 \\
\hline Campania & -0.81 & 0.72 & -1.12 \\
\hline Apulia & 1.42 & 0.81 & 1.75 \\
\hline Basilicata & -0.24 & 0.40 & -0.60 \\
\hline Calabria & -0.71 & 0.59 & -1.20 \\
\hline Sicily & -1.20 & 0.78 & -1.54 \\
\hline Sardinia & -0.56 & 1.38 & -0.41 \\
\hline
\end{tabular}

$$
\beta R=\frac{\beta r e s}{\beta r e c}
$$

By graphing the results of this study through the use of the Cartesian axes and placing on the horizontal axis the resistance index and on the ordinate the recovery index, it shows four cases:

1) In the first quadrant we find the regions that have a higher resistance index greater than zero and recovery index of 1 .

2) In the second quadrant we find the regions that have a lower resistance index to zero and a greater recovery index of 1 .

3) In the third quadrant we find the regions that have a lower resistance index to zero and a recovery index less than 1.

4) In the fourth quadrant are the regions that have a higher resistance index to zero and a recovery index less than 1 .

So, in the first quadrant are the more resilient regions, those less resilient in the third quadrant, and finally in the second and fourth quadrant are the regions that have obtained intermediate results. Below is Table 6 showing, in detail, the regions present in each quadrant. 
Table 6. The regions present in each quadrant.

\begin{tabular}{cc}
\hline $\begin{array}{c}\text { First quadrant } \\
\text { (resistance index }>0 \text {; recovery index }>1)\end{array}$ & $\begin{array}{c}\text { Second quadrant } \\
\text { (resistance index }<0 ; \\
\text { recovery index }>1)\end{array}$ \\
\hline Lazio-Trentino Alto Adige-Valle d'Aosta-Veneto-Lombardia & Sardegna-Umbria-Emilia Romagna \\
Third quadrant & $\begin{array}{c}\text { Forth quadrante } \\
(\text { resistance index }>0 ; \\
\text { recovery index }<1)\end{array}$ \\
Piemonte-Sicilia-Calabria-Basilicata-Campania-Marche-Toscana-Liguria-Friuli Venezia Giulia & Abruzzo-Molise-Puglia \\
\hline
\end{tabular}

From the diagram (Figure 2) just indicated Lazio, Trentino Alto Adige, the Valle d'Aosta, Veneto and Lombardy turn out to be the most resilient regions, while Piedmont, Sicily, Calabria, Basilicata, Campania, Marche, Tuscany, Liguria and Friuli Venezia Giulia are the regions with less resilient capacity. Sardinia, Umbria and Emilia Romagna have a good recovery ratio but a very bad sign of resistance. It is clearly that the regions that despite suffer most dramatically the effects of crisis on employment have increased resilience over time. Unlike the regions of Abruzzo, Puglia and Molise that show a good index resistance to the difficulties of the crisis in terms of employment which then have a bad index of employment recovery.

In addition to the format just mentioned considering the resilience index previously obtained, it is possible to classify the Italian regions among those who have obtained a positive value and those who have obtained a negative value. Figure 3 shows graphically the resilient and non-resilient regions. A region is resilient if it has a good economic performance and is able to maintain it in the long term even in the face of adverse conditions and/or shocks of social, economic, environmental nature, through a constant adaptation process. However the presence of regions with greater resilience does not seem to confirm the traditional dualistic scheme of the country. The most resilient regions appear to be concentrated in the North-East and South-East of Italy (except for Lazio).

\subsection{Re-Shoring and Economic Resilience: Discussion}

At the end of this measurement exercise, we can compile the final results both of the re-shoring phenomena in Italy divided by regions and regional resilience, with the aim of demonstrating that there is a relationship at regional level between the phenomenon of the return of productive activities and the resilience of Italian territories and regions.

The more regions show resilience and recovery capacity in the face of the recent economic crisis, the more re-shoring phenomena seem to be able to recovery. Table 7 summarizes data from regions that have identified re-shoring phenomena, companies that have in the past relocated their production activities, and the resilience values of Italian regions by highlighting those that show positive values of re-shoring and resilience. 


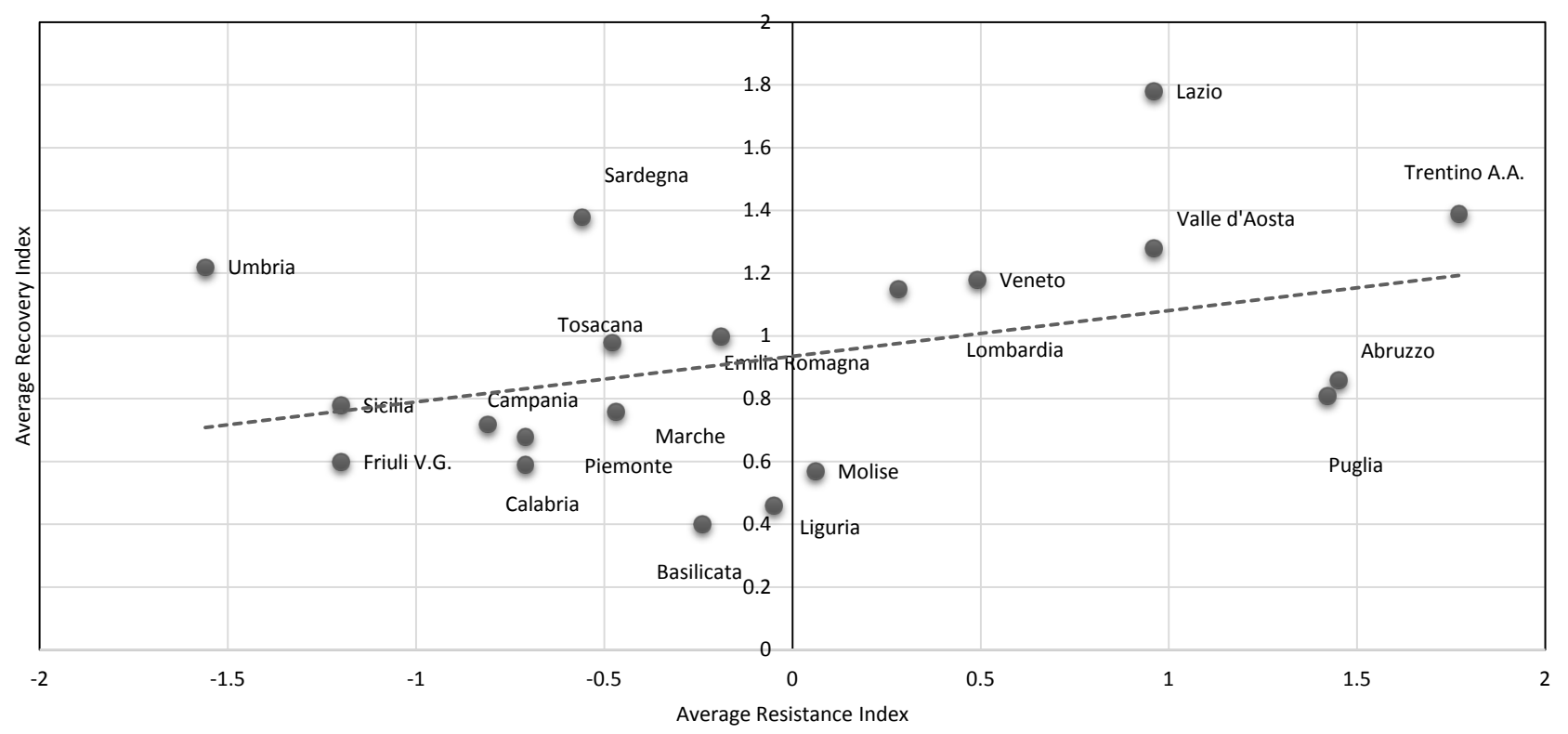

Figure 2. Resistance and recovery of Italian regions ${ }^{6}$.

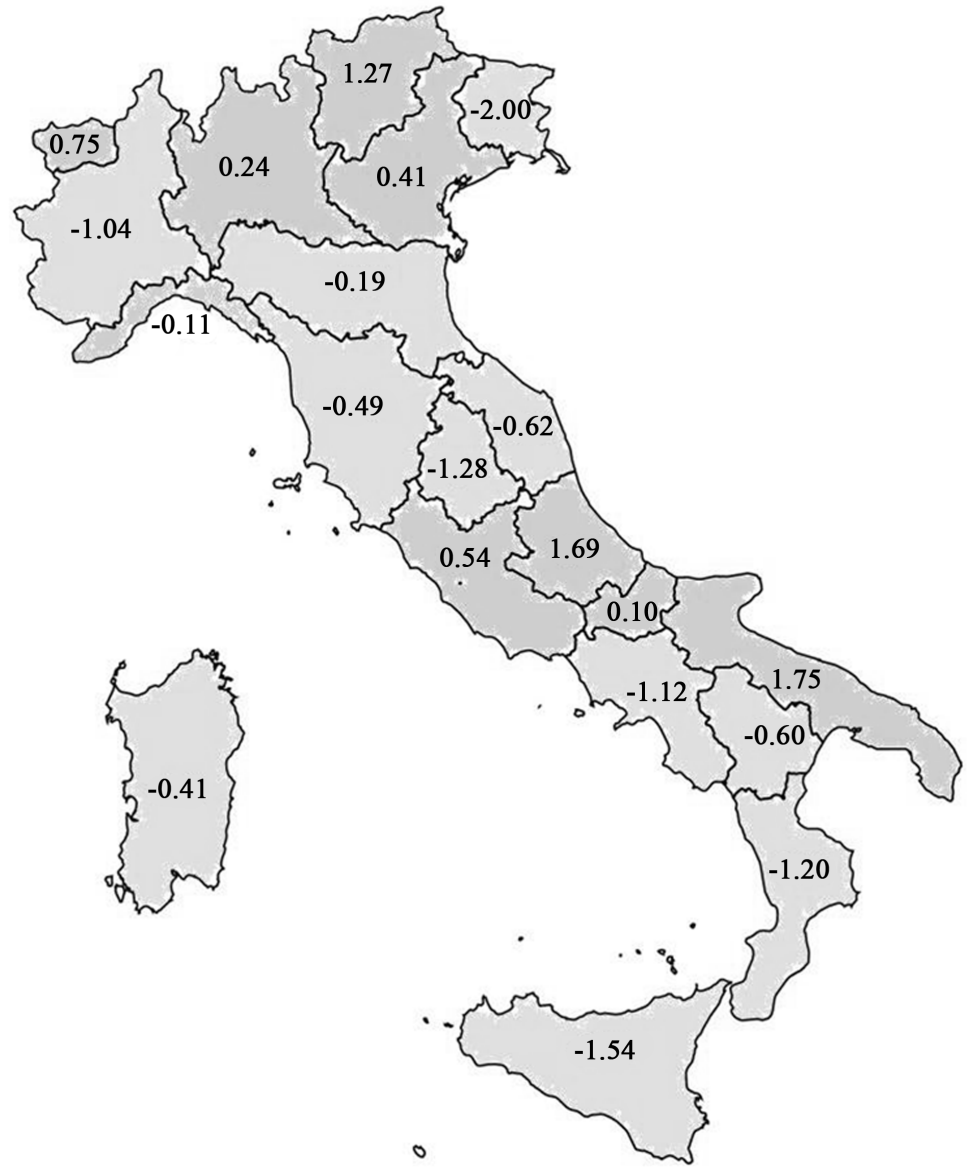

Figure 3. The allocation of resilience in Italy.

${ }^{6}$ The resistance index is calculated in the three periods of recession (1970-1973), (1991-1995), (2008-2010) while the recovery rate is calculated in the following two periods to recessions (1973-1990), (1996-2007). 
Table 7. Re-shoring and resilience.

\begin{tabular}{|c|c|c|}
\hline REGIONI & Re-shoring Decisions & Index of Resilience \\
\hline Apulia & 2 & 1.75 \\
\hline Abruzzo & 1 & 1.69 \\
\hline Trentino Alto Adige & 3 & 1.27 \\
\hline Valle d'Aosta & 0 & 0.75 \\
\hline Lazio & 1 & 0.54 \\
\hline Veneto & 36 & 0.41 \\
\hline Lombardia & 18 & 0.24 \\
\hline Molise & 0 & 0.10 \\
\hline Liguria & 5 & -0.11 \\
\hline Emilia Romagna & 22 & -0.19 \\
\hline Campania & 2 & -0.41 \\
\hline Tuscany & 9 & -0.49 \\
\hline Basilicata & 0 & -0.60 \\
\hline Marche & 9 & -0.62 \\
\hline Piedmont & 7 & -1.04 \\
\hline Sardinia & 0 & -1.12 \\
\hline Calabria & 0 & -1.20 \\
\hline Umbria & 2 & -1.28 \\
\hline Sicily & 0 & -1.54 \\
\hline Friuli Venezia Giulia & 6 & -2.00 \\
\hline
\end{tabular}

From Table 7 emerges an articulated framework in which the presence of a degree of significant resilience certainly represents a major element in possible re-shoring decisions. The analysis shows that there are 62 cases of back-shoring entrepreneurial decisions in the presence of regional resilience capacities above 0 , and with values from 0 to -1 there are 47 cases of back-shoring. With values below -1 , there are only 15 cases with some regions where even back-shoring experiences (Sicily, Calabria, Sardinia) are not known.

We can see how different endowments of economic and social resilience can compete with re-shoring decisions in the various Italian regions and we can divide Italy into three macro-regions where the various Italian regions are analyzed in terms of re-shoring and significant resilience. In this geographic and economic articulation we can distinguish: 1) a first group of regions that have achieved positive results both for resilience and for re-shoring phenomena; 2) a second group which, while being non-resilient, has detected some re-shoring phenomena; 3) a third group of regions showing negative results for both economic resilience and re-shoring values. The figure (Figure 4) shows the articulation of the three geographic areas. 


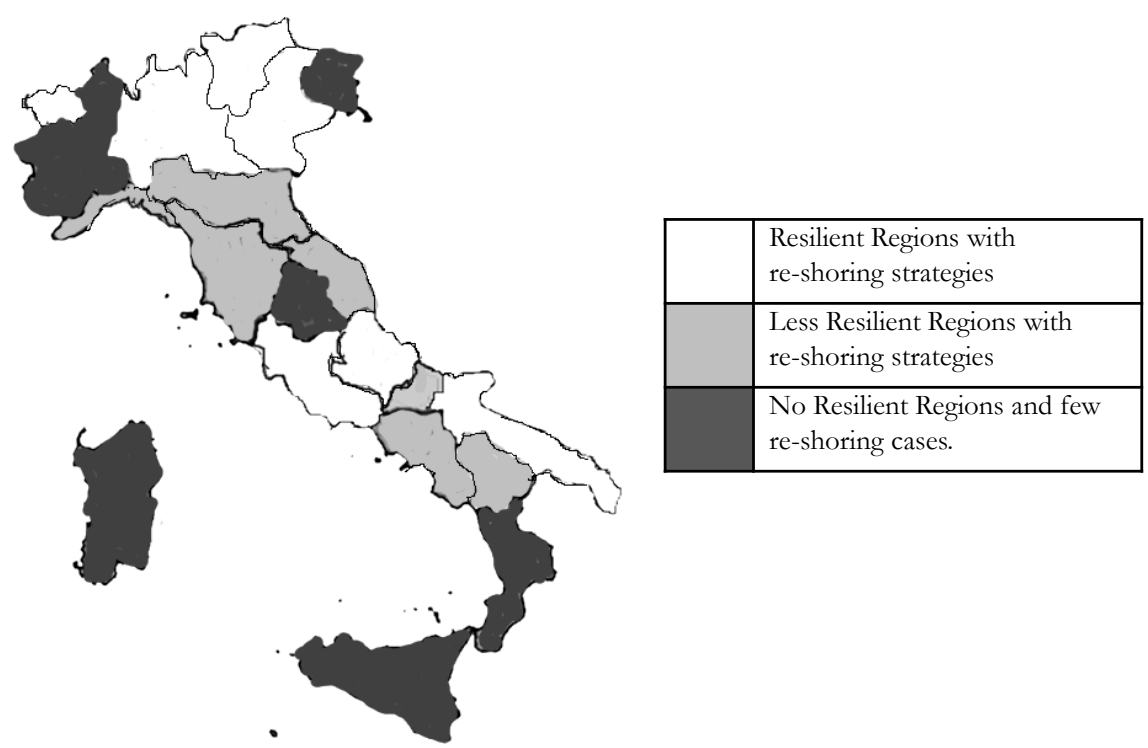

Figure 4. Italian regions: Economic resilience and re-shoring attitude.

In analyzing these results we can see there are some regions that did not achieve satisfactory results in both measurements are those of dark gray color, i.e. Sicily, Sardinia, Calabria, Piedmont, Umbria, Friuli Venezia Giulia. The other group of regions, with the exception of Emilia Romagna showing a significant number of re-shoring experiences, are regions that we can call "bearings" between those that show totally negative results and those that have positive performance for both values. The figure also shows that there is no geographical continuity between the Italian regions and re-shoring and resilience experiences take on relevance in decisions but not in an exclusive way. There is not a territorial dualism but it is possible to underline a diversification from one extreme of the country to the other. Finally, these data seem to confirm, in an entirely embryonic manner and with the necessary specifications on the level of individual entrepreneurial experiences, the initial hypotheses of a direct relationship between resilience and re-shoring decisions. These first results need further insights through even micro analysis.

Research has shown, however, that in some regions there is a relationship between the economic resilience index and the re-shoring choices of businesses, pointing out that the territorial element is a major indicator in entrepreneurial choices. Regions with a higher level of economic resilience are the ones that reacted better to the latest economic shocks, confirming an entrepreneurial fabric and an even more competitive edge.

We can therefore assert that resilience at regional level is a necessary but not indispensable element for investment return decision-making. Certainly, in addition to the resilience and recovery of territories at regional level, other dimensions are also relevant, such as the characteristics of the local productive and entrepreneurial system, the degree of openness and innovation of the local economy or other dimensions more explicitly sectoral and entrepreneurial. 
Ultimately, despite the fact that there is an exclusive and direct relationship between re-shoring and resilience, the latter is still one of the important elements to be considered in the regional economy and entrepreneurial and sectoral choices, especially in those areas that show presence of significant manufacturing and manufacturing districts and/or clusters.

\section{Conclusions}

The main results of our study should be viewed in the light of the relation between re-shoring and resilience in the Italian regions. The analysis presented in this paper, starts from an analysis of the main literature regarding the re-shoring phenomenon. The increasing attention on re-shoring phenomenon by the scientific community and policy makers will involve a revision of traditional business models both for policy implications, and for managerial strategies to adopt and this represents an occasion to rethink on the sector and on the sustainability and in order to re-qualify Italian productions.

At the end of this research, we can conclude that the presence of resilience is definitely needed but not indispensable for recognizing a correlation with entrepreneurial decisions and re-shoring. While acknowledging the importance of the link between regional resilience and re-shoring decisions, this research does not, therefore, demonstrate the exclusive existence of a direct link between the presence of resistance and recovery capacity on the territory of asymmetric shocks to the economy and the increasing number of decisions made by Italian companies to repatriate part or all of the delocalized investments. Rather, the proposed scheme confirms the existence of a general relationship between economic resilience and re-shoring phenomena but not exclusively.

This analysis can contribute to the definition of certain contextual policies that can help the resumption of productive activity and regional economies affected by the economic and financial crisis also through the contribution and enhancement of return on investment and thus back-shoring.

In Italy, to date, little has been done for the re-shoring phenomenon. The most important category economic associations, particularly in the fields of fashion and footwear, have long been calling for concrete planning for tax reforms, IRAPs and recruitment, with the aim of also favoring back-shoring. One of the main reasons for re-shoring for Italian companies is made in Italy. In this regard, it is recognized as a central role for consumers and international markets in the face of growing demand for entirely made-in productions [14].

This analysis can contribute to the definition of certain contextual policies that can help the resumption of productive activity and regional economies affected by the economic and financial crisis also through the contribution and enhancement of return on investment and thus back-shoring.

In light of the examples just presented, it can be concluded that the economic and social resilience of regional territories and some Italian manufacturing promotion policies in support of Made in Italy can help to strengthen the recent 
back-shoring phenomena, representing the elements of the new developments of the regional economy. Several authors [18] [42] support the hypothesis that more development can be part of a business network logic, emphasizing, for example, their natural location in the Territorial Logistics Chains structurally linked to the economy of the sea, particularly promising in the economy of the Mezzogiorno. Consequently, thinking back-shoring as a further phenomenon to accompany specific national policies in the context of a more comprehensive revival of the country's competitiveness is certainly an open-minded challenge both in theoretical and more practical terms and in territorial development policies and regional. Focusing our attention on Italy, it comes to light that a higher coordination between national Government, Regional government and the private sector to promote made in Italy is necessary, offering: efficient infrastructures; location opportunities; employees and competences; subsidies and tax reliefs.

\section{References}

[1] Fratocchi, L., Ancarani, A., Nassimbeni, G., Valente, M.E. and Zanoni, A. (2012) Le strategie di backshoring e nearshoring nelle imprese manifatturiere italiane: caratterizzazione del fenomeno e comparazione internazionale. Rapporto dell'Istituto nazionale per il Commercio estero (ICE), L'Italia nell'economia internazionale.

[2] Fratocchi, L., Di Mauro, C., Barbieri, P., Nassimbeni, G. and Zanoni, A. (2014) When Manufacturing Moves Back: Concepts and Questions. Journal of Purchasing and Supply Management, 20, 54-59. https://doi.org/10.1016/j.pursup.2014.01.004

[3] Fratocchi, L., Ancarani, A., Barbieri, P., Di Mauro, C., Nassimbeni, G., Sartor, M., Vignoli, M. and Zanoni, A. (2015) Il back-re-shoring manifatturiero nei processi di internazionalizzazione: Inquadramento teorico ed evidenze empiriche. Italian Journal of Management, 33, 125-147.

[4] Di Mauro, C., Fratocchi, L., Orzes, G. and Srtor, M. (2017) Offshoring and Backshoring: A Multiple Case Study Analysis. Journal of Purchasing and Supply Management, 24, 108-134.

[5] Ellram, L.M. (2013) Offshoring, Re-shoring and the Manufacturing Location Decision. Journal of Supply Chain Management, 49, 3-5.

[6] Kinkel, S., Lay, G. and Maloca, S. (2007) Development, Motives and Employment Effects of Manufacturing Off-Shoring of German SMEs. International Journal of Entrepreneurship and Small Business, 4, 256-276.

https://doi.org/10.1504/IJESB.2007.013251

[7] Kinkel, S. and Maloca, S. (2009) Drivers and Antecedents of Manufacturing Off-Shoring and Backshoring-A German Perspective. Journal of Purchasing and Supply Management, 15, 154-165. https://doi.org/10.1016/j.pursup.2009.05.007

[8] Kinkel, S. (2012) Trends in Production Relocation and Backshoring Activities: Changing Patterns in the Course of the Global Economic Crisis. International Journal of Operations \& Production Management, 32, 696-720. https://doi.org/10.1108/01443571211230934

[9] Kinkel, S. and Zanker, C. (2013) New Patterns of German Production Relocation and Back Shoring Activities after the Global Economic Crisis? European Operations 
Management Association (EurOMA).

[10] Kinkel, S. (2014) Future and Impact of Backshoring. Some Conclusions from 15 Years of Research on German Practices. Journal of Purchasing \& Supply Management, 20, 63-65. https://doi.org/10.1016/j.pursup.2014.01.005

[11] ESPON (2012) Economic Crisis: Resilience of Regions. Inception Report, Espon-Cardiff University.

[12] Benito, G.R.G. and Welch, L.S. (1997) De-Internationalization. MIR: Management International Review, 37, 7-25.

[13] Benito, G.R.G., Petersen, B. and Welch, L.S. (2011) Mode Combinations and International Operations. Theoretical Issues and an Empirical Investigation. Management International Review, 51, 803-820. https://doi.org/10.1007/s11575-011-0101-4

[14] Musso, F., Francioni, B. and Pagano, A. (2012) The Role of Country of Origin in Supporting Export Consortia.

[15] Gray, J.V., Skowronsky, K., Esenduran, G. and Rungtudanatham, M.J. (2013) The Re-shoring Phenomenon: What Supply Chain Academics Ought to Know and Should Do. Journal of Supply Chain Management, 49, 27-33.

[16] Holz, R. (2009) An Investigation into Offshoring and Backshoring in the German Automotive Industry. PhD Thesis, University of Wales, Swansea.

[17] Mouhoud, E.M. (2007) Mondialisation et Délocalisation des Entreprises. Éditions La Découverte, Parigi.

[18] (2016) Uni-CLUB MoRe Back-Re-shoring Research Group. Eurofound.

[19] ICE (2015) Parola d'ordine Re-shoring, rilocalizzare ora è un must. n. 8/15, Newsletter Diplomazia Economia Italiana.

[20] KPMG Advisory S.p.A. (2015) The Italian Way. L'industria italiana tra re-shoring e nuovi modelli di sviluppo (a cura di). Ministero dello Sviluppo Economico.

[21] Coe, N., Dicken, P. and Hess, M. (2008) Global Production Networks: Realizing the Potential. Journal of Economic Geography, 8, 271-295. https://doi.org/10.1093/jeg/lbn002

[22] Gereffi, G. and Fernandez-Stark, K. (2011) Global Value Chain Analysis: A Primer. Center on Globalization, Governance \& Competitiveness (CGGC), Duke University, Durham, NC.

[23] Williamson, J. (2012) Growing Supply Chain Disruption Encourages Re-Shoring. Manufacturing Digital, 13 August 2012.

[24] Martin, R. (2011) Regional Economic Resilience, Hysteresis and Recessionary Shocks. Journal of Economic Geography, 12, 1-32.

[25] Sammie, J. and Martin, R. (2010) The Economic Resilience of Regions: Towards an Evolutionary Approach. Cambridge Journal of Regions, Economy and Society, 3, 27-43. https://doi.org/10.1093/cjres/rsp029

[26] Holling, C.S. and Gunderson, L.H. (2002) Resilience and Adaptive Cycles. In: Gunderson, C.S. and Holling, C.S., Eds., Panarchy: Understanding Transformation in Human and Natural Systems, Island Press, Washington DC, 25-62.

[27] Holling, C.S. (1996) Engineering Resilience versus Ecological Resilience. In: Schulze, P., Ed., Engineering within Ecological Constraints, National Academy Press, Washington DC.

[28] Holling, C.S. (1973) Resilience and Stability of Ecological System. Annual Review of Ecology and Systematics, 4, 1-23.

https://doi.org/10.1146/annurev.es.04.110173.000245 
[29] Pimm, S.L. (1984) The Complexity and Stability of Economic System. Nature, 307, 321-326. https://doi.org/10.1038/307321a0

[30] Walker, B., Gunderson, L., Kinzig, A., Folke, C., Carpenter, S. and Schultz, L. (2006) A Handful of Heuristic and Some Propositions for Understanding Resilience in Socio-Ecological Systems. Ecological and Society, 11, 13.

[31] Gunderson, L. and Pritchard, L. (2002) Resilience and the Behaviour of Large Scale System. Island Press, Washington DC.

[32] Perrings, C. (2006) Resilience and Sustainable Development. Environment and Development Economics, 11, 417-427. https://doi.org/10.1017/S1355770X06003020

[33] Hill, E.W., Wial, H. and Wolman, H. (2008) Exploring Regional Economic Resilience. Working Paper, Institute of Urban and Regional Development, University of California.

[34] Christopherson, S., Michie, J.E and Tyler, P. (2010) Regional Resilience: Theoretical and Empirical Perspectives. Cambridge Journal of Regions, Economy and Society, 3, 3-10. https://doi.org/10.1093/cjres/rsq004

[35] Clark, J., Huang, H.-I. and Walsh, J. (2010) A Typology of "Innovation Districts": What It Means for Regional Resilience. Cambridge Journal of Regions Economy and Society, 3, 121-137. https://doi.org/10.1093/cjres/rsp034

[36] Archibugi, D. and Lundvall, B.A. (2001) The Globalist Learning Economy. Oxford University Press, Oxford.

[37] Pendall, R., Foster, K.A. and Cowell, M. (2008) Resilience and Regions: Building Understanding of the Metaphor. Mimeo Institute of Urban and Regional Development, Cornell University, Ithaca, NY.

[38] Capineri, C., Celata, F., De Vincenzo, D., Dini, F., Randelli, F. and Romei, P. (2014) Oltre la Globalizzazione Resilienza/Resilience. Memorie Geografiche, No. 12.

[39] Graziano, P. (2012) Rischio, vulnerabilità e Resilienza territoriale. Quaderni del Dipartimento di Scienze Economiche e Sociali, No. 87.

[40] Briguglio, L. (2003). The Vulnerability Index and Small Island Developing States: A Review of Conceptual and Methodological Issues. Paper prepared for the AIMS Regional Preparatory Meeting on the Ten Year Review of the Barbados Programme of Action, Praia, Cape Verde, 1-5 September 2003.

[41] Lagravinese, R. (2015) Regional Resilience and Rising Gaps North-South: The Case of Italy. Cambridge Journal of Regions, Economy and Society Advance, 8, 331-342. https://doi.org/10.1093/cjres/rsv006

[42] SVIMEZ (2015) Rapporto SVIMEZ sull'Economia del Mezzogiorno. Il Mulino. 